\title{
Evaluation of Bactericidal activity of Garcinia gummi-gutta and Gymnema Sylvestre- A plant of Ethano medicinal Importance
}

\author{
Vibala.B.V, P.K.Praseetha
}

\begin{abstract}
Antibiotic defiance in bacterial is a satisfactory obstacle in the latest world. Day-to-day novel dopes are being intact to defeat this drawback. The goal of this is trained used to be to check antimicrobial resistance of the Garcinia gummi-gutta and Gymnema Sylvestre. The dried fruit of G. Gummi-gutta and G.Sylvestre crops are located in a southern state of India. The extract of dried fruit of G. Gummi-gutta and G.Sylvestre leaf was once ready through using specific solvent of Ethyl Acetate. These ready extracts have been used for evaluation of antibacterial ability in opposition to three Gram-positive bacterial stains (Escherichia coli, Salmonella typhi, Pseudomonas aeruginosa) and two gram-negative bacterial stains (Streptococcus, Staphylococcus aureus). The antimicrobial ability was appraised by Disc diffusion assay of G. Gummi-gutta and G.Sylvestre. The zone of inhibition used to be determined at the concentration of $(500 \mu \mathrm{g} / \mathrm{ml})$ in G.Gummi-gutta Streptococcus\& Pseudomonas aeruginosa (14mm), Staphylococcus aureus\& Salmonella typhi $(9 \mathrm{~mm})$, Escherichia coli $(8 \mathrm{~mm})$. The zone of inhibition was once determined at the concentration of $(500 \mu \mathrm{g} / \mathrm{ml})$ in G.Sylvestre.The Streptococcus(11mm), Staphylococcus aureus\& Escherichia coli (9mm), Salmonella typhi(10mm), Pseudomonas aeruginosa $(8 \mathrm{~mm})$ respectively. Due to the fact, the extract confirmed a wide spectrum of the antimicrobial undertaking of each Gram positive and gram negative bacterial isolates. Comparative reports of the G. Gummi-gutta and G.Sylvestre.The nice one among G.Sylvestre. Can be utilized as a bio preservative or therapeutic agent to prevent a few illnesses. The dried leaves of

G.Sylvestre would characterize a novel antimicrobial obtain with steady, adoptive energetic compounds that may prove a scientific base for the consumer in recent treatment.
\end{abstract}

\section{Keywords: Antibacterial activity, G.Sylvestre}

\section{INTRODUCTION}

Medicinal crops and herbs are of the best significance to the wellbeing of character and communities. The use of normal drug treatments holds a pleasant promise as and simply to be had source as mighty medicinal agents to cure a few ailments. The sector well being or World Health Organization (WHO) assessment that $80 \%$ of the occupancy of constructing international locations still relies on common drugs, in general plant medicinal drugs, for their predominant well-being care needs [1]. Globally researchers are utilizing extracts of plants for his or her antibacterial and antifungal properties [2]. Despite the existence of herbal medicines over several centuries, handiest few numbers of species have been

Revised Version Manuscript Received on September 16, 2019.

Vibala.B.V, Department of Nanotechnology,Noorul Islam center for higher education, Kumaracoil, Tamilnadu - 629180, India

(Email: : bala10101990@gmail.com)

P.K.Praseetha Department of Nanotechnology,Noorul Islam center for higher education, Kumaracoil, Tamilnadu - 629180, India studied for their utility. Nevertheless, within the latest prior, expand in research evidence indicates the positive function of natural medicinal crops within the prevention or manipulate of one of the vital metabolic issues like obesity, Diabetes, Coronary ailments, melanoma, and many others. The regularly growing bacterial resistance to present medicinal drugs is a major problem in antimicrobial treatment and necessitates continuing study into new courses of antimicrobials. Biomolecules of the plant starting place seem to be one of the most possible choices for the management of these antibiotic-resistant human and plant-microorganism and therefore within the investigation, fresh and dry fruit rind extract of Garcinia gummi-gutta and Gymnema Sylvestre was demonstrated for its efficacy towards the inhibition of human pathogens. The resistance of microorganisms and the looks of stains with decreased venerability to antibiotics are continually increasing due to the selective consume of mercantile antibacterial therapy of vitiating illnesses [3]. Furthermore, excessive and adverse part results (akin to hypersensitivity, allergic reactions, immunosuppressant, etc.) are more often than not associated with well known synthetic antibiotics and are excessive important international problems in cure virulent diseases[4].Therefore, there's a require to examine new contamination against methods to restraint microbial defilement.

The Genus Garcinia comprises about 200 species; the place 35 species are discovered within the two ecosystems of India, the Western Ghats and The Himalayan foothills [5].Garcinia gummi-gutta is a majority species observed in the Western Ghats[6].G. Gummi-gutta goes to ones Guttiferae. It's a hardwood underutilized therapeutically fruit crop, the place its fruits are used in meals mixture, chiefly in curries. Garcinia gummi-gutta is a small or average-sized evergreen tree growing to a top of 20 meteres additionally noticeable as shrubs. The bark is dark and gentle. The branches are thin and delicate, drooping or horizontal. Leaves are reverse, petiolate, darkish inexperienced, shining, elliptic to obviate and glabrous, starting from $2 \frac{1}{2}$ to $3 \frac{1}{2}$ inch in length and 1 to $1 \frac{1}{2}$ inch huge. The tree flora for the period of December to February and it fruits from March to June [7]. vegetation are seen in clusters of 420, mainly crimson, although some bushes have yellow ones also. The Fruit is a green, ovoid berry, having 1 to $1 \frac{1}{2} 2$ inch in diameter.The fruits are yellow or purple in color when ripe, having 6-8 grooves. 
Fruit pulp includes 5 to eight huge seeds which can be surrounded by means of a succulent aril. Clusiaceae includes four main courses of compounds reminiscent of xanthones, coumarins, bi flavonoids, and benzophenones. Garcinia is an efficient source of treatment and has been investigated commonly by many researchers in reference to its medicinal houses and more than a few other cytotoxic effects. It has been proven to include a type of secondary metabolites corresponding to xanthones, flavonoids, and benzophenones.

Gymnema Sylvestre (G. Sylvestre) (Asclepiadaceae) is a tropical plant found in the places of Africa, Australia, the central and western India [8].It is mainly used for an anti diabetic[9].Gymnema Sylvestre leaves are used in pharmaceutical exchange[10].Gymnemic acids were extracted to the plant and used in anti-diabetic, anti-sweetener and antihypercholesterolemi.It also has stomachic, diuretic and cough suppressant houses. Mainly antimicrobial properties are suggested in these plants [11].Additionally, it possesses hepatoprotective, and ant saccharine activities [12].The plant is trained to the choice for analysis in the center and ordinary $[13,14,15]$. Importantly medicinal plants are restrained and achieved antimicrobial studies are recreation against disease-causing microorganisms.[16]

\section{MATERIALS AND METHODS}

\section{a) Sample collection}

The dried fruits of Garcinia gummi-gutta and Gymnema Sylvestre leaf which was readily available within the retail outlets (Vernacular title: Kodampulli, Sirukurinjon) was once bought from a neighborhood place in Kanyakumari. The regional botanist has authenticated the sample. These two samples have been maintained in particular room temperature.

\section{b) Extraction procedure}

The fruit and dried leaves (200gm) has been successively extraction by the soxhlet apparatus. Ethyl acetate solvent used to extraction was carried out. The extract has been centered and distilling in a rotary evaporator. The extract was preserved in the container kept at 4-5 mins and further use.

\section{c) Chemicals, Media and Antibiotic}

Ethyl acetate solvent, Nutrient broth, and Nutrient agar, Muller Hinton agar (MHA), antibiotic Ampicillin has been bought from Life Tech Research center, Chennai.

\section{d) Test organisms}

The antibacterial properties were investigated the selected five human pathogenic bacteria to include Gram-negative (Escherichia coli (MTCC B1560), Salmonella typhi, Pseudomonas aeruginosa (MTCCB2297), and Gram-positive (Streptococcus (MTCC B2274), Staphylococcus aureus (MTCC B3160) bacteria. The entire bacterial strains were pure isolates got from and had been maintained in nutrient agar.

\section{e) Preparation of Inoculums:}

Nutrient agar slant used to the stock culture was maintained at $4^{\circ} \mathrm{C}$. Then the culture was transferred to the

tubes. The tubes contain nutrient broth incubated at $24 \mathrm{hrs}$ at $37^{\circ} \mathrm{C}$.

\section{f) Determination of Antimicrobial Activity}

\section{g) g) Sensitivity Discs}

Whatman no1 filter paper used to the sterile sensitivity disc (5 diameters) prepared. The disc was sterilized and autoclaving at a particular temperature for $121^{\circ} \mathrm{C}$ for 5 mins. The discs were soaked within the extracts for 10 minutes and allowed to dry. The dried discs carrying the bioactive compounds were used for disc diffusion assay.

\section{h) Preparation of Bacterial Suspension}

The peptone water used to the pure isolated colonies of bacterial colonies had been inoculated and incubated at $37^{\circ} \mathrm{C}$ for $48 \mathrm{hrs}$ and have been used as inoculums for lawn culture on Mueller Hinton Agar (Hi-Media) for assaying the antibacterial recreation of the extracts.

\section{i) Agar Disc Diffusion Method:}

The Muller Hinton agar (MHA) medium was used to the disc diffusion approach of antibacterial extracts. The Muller Hinton agar (MHA) medium was poured in the Petri plate. After that, the medium was inoculated solidified and the plate with a sterile swap with the bacterial suspension. The different concentration (Concentration: $1000 \mu \mathrm{g}, 750 \mu \mathrm{g}$, and $500 \mu \mathrm{g}$ ) the disc were placed at MHA plates and add $20 \mu \mathrm{l}$ of the sample. Finally, the antimicrobial properties were determined with the measuring of the zone of inhibition (diameter)

\section{j) Zone Analysis}

After incubation, the antibacterial activity of the extracts in opposition to each bacterial stain was once assayed through the nearest $\mathrm{mm}$ the zone of inhibition has measured the diameter. Then the results have been recorded and when compared.

\section{RESULTS AND DISCUSSION}

a)Antibacterial activity of Garcinia gummi-gutta

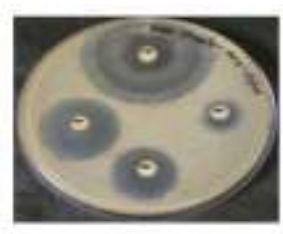

(a) Streptococcus

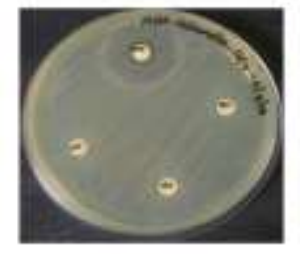

(d) Salmonella typhi

Fig 1: Zone of inhibition of dry rind of Garcinia gummi-gutta Gram Positive \& Gram Negative Test organisms

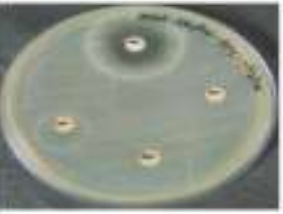

(b) Staphylococeas aureus

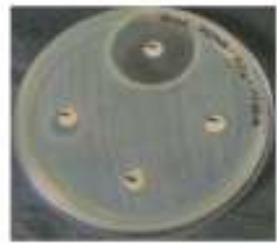

(e) Psendomonas aeruginosa

(c) Ecoli

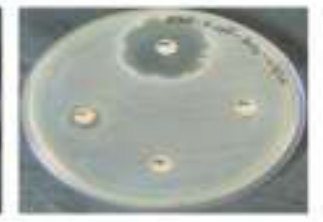

\& Sciences Publication 


\begin{tabular}{|c|c|c|c|c|}
\hline \multirow{3}{*}{ Organisms } & & $\begin{array}{l}\text { e of I } \\
\text { (m }\end{array}$ & & \multirow{3}{*}{$\begin{array}{l}\text { Antibiotic } \\
\text { (lmg mil) }\end{array}$} \\
\hline & \multicolumn{3}{|c|}{ Concentration(ug/ml) } & \\
\hline & 1000 & 750 & 500 & \\
\hline Streptococcus & 28 & 23 & 14 & 48 \\
\hline Staphylocaccus aurens & 14 & 9 & 9 & 30 \\
\hline Escherichia coli & 12 & 8 & 8 & 28 \\
\hline Salimonellit typhi & 11 & 9 & 9 & 27 \\
\hline Psendomonas aeruginosa & 28 & 23 & 14 & 48 \\
\hline
\end{tabular}

Table 1: Invitro Antibacterial properties of Garcinia gummi-gutta on Test organisms (Identified by the diameter of Inhibition zone)

\section{b) Antibacterial activity of Gymnema Sylvestre}
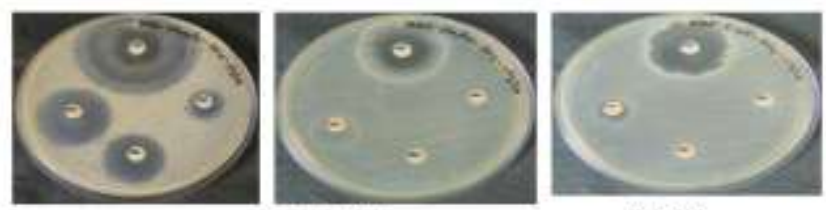

(a) Streptococcus (b) Staphylococeas sureus

(e) E.eoti
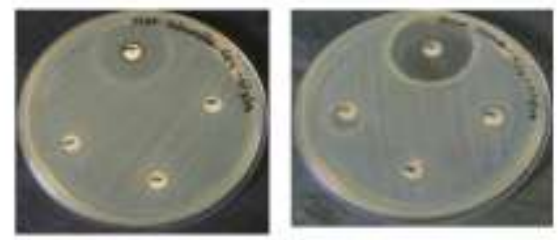

(d) Salmonellils typhi

(e) Pseudomonas aeraginosa

Fig 2: Zone of inhibition of Gymnema Sylvestre Gram Positive \& Gram Negative Test organisms

\begin{tabular}{|c|c|c|c|c|}
\hline \multirow{3}{*}{ Organisms } & \multirow{2}{*}{\multicolumn{3}{|c|}{$\begin{array}{l}\text { Zone of Inhibition } \\
\text { (mm) }\end{array}$}} & \multirow{3}{*}{$\begin{array}{l}\text { Antibiotic } \\
\text { (lmgiml) }\end{array}$} \\
\hline & & & & \\
\hline & 1000 & 750 & 500 & \\
\hline Streptococcus & 20 & 17 & 11 & 47 \\
\hline Stophylacoccus awreus & 10 & 9 & 9 & 28 \\
\hline Escherichia coli & 13 & 9 & 9 & 25 \\
\hline Saimonelila aphi & 14 & 10 & 10 & 29 \\
\hline Pseudomonas aeruginosa & 10 & 8 & 8 & 30 \\
\hline
\end{tabular}

Table 2:Invitro Antibacterial properties of Gymnema Sylvestre on Test organisms (Identified by the diameter of Inhibition zone)

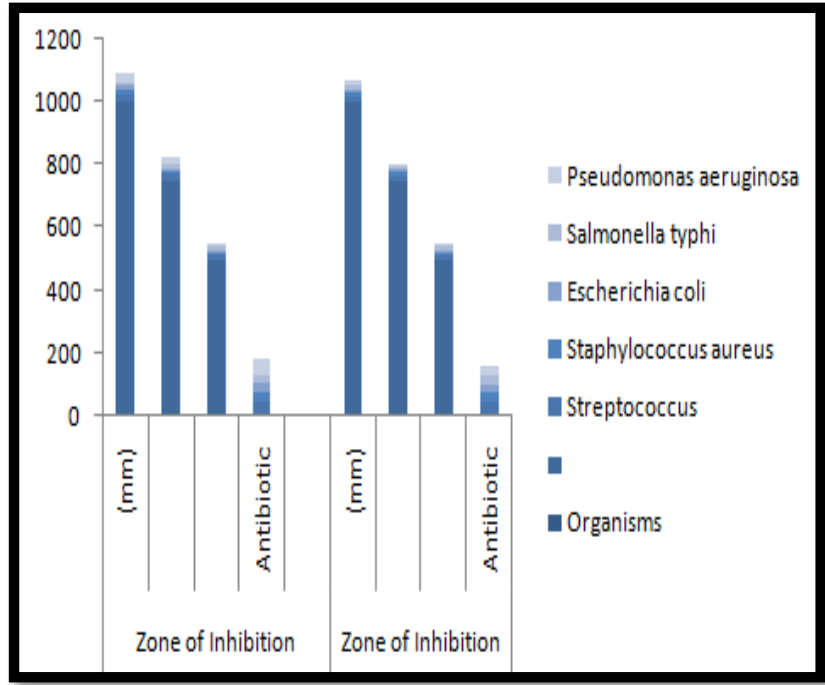

Fig 3: Comparative and statistical analysis of the $G$. gummi-gutta and G.Sylvestre (Determined by the diameter of Inhibition zone)

\section{RESULT \& DISCUSSION}

The antibacterial activity of Ethyl acetate extract of $G$. Gummi-gutta and G.Sylvestre has assayed Invitro through agar disc diffusion method in opposition to bacterial species. Table 1\&2 summarizes microbial growth inhibition. The huge antibacterial endeavor of the plant extract was once similar to Ampicillin $(20 \mu \mathrm{g} / \mathrm{ml})$. The Antimicrobial pastime of the bacterial strains was prepared. Comparative study of antibacterial activity of those medicinal crops. G.Sylvestre confirmed very best antibacterial activity against gram-positive and gram-negative organisms. The Antimicrobial endeavor of ethyl acetate in opposition to gram positive and gram negative organisms increases as the volume of extracts increases.

\section{CONCLUSION}

G. Gummi-gutta and G.Sylvestre Posses' significant antibacterial activity. Extra study is needed for the isolation and identification of energetic precept present within the extracts which could almost certainly be exploited for pharmaceutical use. Additional studies have got to be equipped to determine the rate of toxicity, their mode of motion and dose-dependent activity against various strains of microorganism. From the above be knowledgeable concluded that the dried scale of leaves of G.Sylvesrae\&.G.Gummi-gutta could characterize a new antimicrobial supply, with steady biologically lively accessories that may set up a scientific base for the use in modern-day remedy. Furthter experiences are needed to remote and represent the bioactive requisites to increase new antimicrobial drug from G. Gummi-gutta and G.Sylvestre. 


\section{REFERENCE}

1 Bakht J,Islam A,Shafi M,Antimicrobial potential of Eclipta Alba by well diffusion method. Pakistan Journal of Botany. 2011; 43:161-166.

2 Gurib-FakimA.Medicinal plants: Traditions of yesterday and drugs of tomorrow. Molecular Aspects of Medicine. 2006; 27:1-93.

3 Zampini J.C.,Vattuone M.A., I. Maria. 2005. Antibacterial activity of Zuccagnia punctata Cav.Ethanolic extract.J Ethanopharmacol., 102: 450-456.

4 Schinor E.C.,Salvador M.J., Ito I.Y.,D.A. Dias. 2007. Evaluation of the antimicrobial activity of crude extracts and isolated constituents from Christa scapigera. Brazilian J Microbiol., 38: 145-149.

5 Parthasarathy U,Nanda Kishore OP (2014) A study on nutrient and medicinal compositions of selected Indian Garcinia species. Current Bioactive Compounds 10: 55-61.

6 Parthasarathy N,Karthikeyan R Biodiversity and population density of woody species in a tropical evergreen forest in Courtallum reserve forest, Western Ghats. India Trop Ecol -1997,38: 297-306.

7 Selvaraj TI,Avadhani M.Medicinal Properties of Malabar Tamarind [Garcinia cambogia (Gaertn.) DESR.]. Int J Pharm Sci Rev Res, 2013; 20: 101-7.

8 Koshy AS, Anila L,Vijayalakshmi NR. Flavonoids from Garcinia cambogia Lower Lipid Levels in Hypercholesteremic Rats. Food Chem, 2001; 72(3): 289-94.

9 Masullo M, Bassarello C, Suzuki H, Pizza C, Piacente S. Polyisoprenylated Benzophenones and an Unusual Polyisoprenylated Tetracyclic Xanthone from the Fruits of Garcinia cambogia. J Agric Food Chem, 2008; 56: 5205-10.

10 Stocklin W.Chemistry and physiological properties of gymnemic acid, the anti-saccharine principle of the leaves of Gymnema Sylvestre. J Agric Food Chem 1969; 17: 704-708.

11 Shanmugasundaram KR, Panneerselvam C, Samudram P, Shanmugasundaram ER. Enzyme changes and glucose

12 utilization in diabetic rabbits: the effect of Gymnema Sylvestre, R.Br. J Ethnopharmacol 1983; 7: 205-234.

13 Kurihara Y.Characteristics of antisweet substances, sweet proteins and, sweetness inducing protein. Crit Rev Food Sci Nutr 1992; 32: 231-252.

14 Bishayee A, Chatterjee M. Hypolipidaemic and antiatherosclerotic effects of oral Gymnema Sylvestre R. Br. Leaf extract in albino rats fed on a high-fat diet. Phytother Res 1994; 8: 118-120.

15 Kapoor LD. CRC Handbook of Ayurvedic medicinal plants. Boca Raton: CRC Press; 1990, p. 200-201.

16 Sative RK, Abhilash P, Fulzele DD. Antimicrobial activity of Gymnema Sylvestre leaf extract. Fitoterapia 2003; 74: 699-701. 